\title{
Investigation of the processes of pollution and reduction of aquatic environment pollution on the example of artificial fish breeding enterprise activities
}

\author{
Maria Zharkova ${ }^{1, *}$, Oksana Paramonova $^{1}$, Natalia Yudina $^{1}$ and Maria Balinskaya ${ }^{1}$ \\ ${ }^{1}$ Don State Technical University, Gagarin sq., 1, Rostov-on-Don, 344003, Russia
}

\begin{abstract}
An important problem of modern society is the provision of the population with ecologically clean food products in quantity, range and quality, which guarantees an increase in their living standards and preservation of health. The solution to this problem is possible with the effective functioning of food market, dynamic development of agroindustrial complex, including production of marketable fish. Significant reserves for increasing fish production are water bodies existing in rural areas and new ponds being built on lands unsuitable for growing agricultural crops. As practice shows, when using inconvenient land for animal husbandry, we can get the following increase in cattle meat $(\mathrm{kg} / \mathrm{ha})$ : in low-lying wetlands -42 , steppe, semi-steppe, desert pastures - 20. At the same time, from 1 hectare of pond mirrors built on such lands, an average of $200-300 \mathrm{~kg}$ of fish is obtained due to natural fish productivity, and with the use of fertilizers, various methods of reclamation and feeding fish up to $1000-1500 \mathrm{~kg} / \mathrm{ha}$. However, on the way to increasing fish productivity is the problem of ensuring water quality of the water body. Thus, the study of the causes and sequence of stages of pollution of water bodies determined the relevance of the research topic [1-3].
\end{abstract}

\section{Introduction}

Issues of research and environmental assessment of the impact of technical objects on aquatic ecosystems, water quality and bioproductivity of water bodies and drains devoted to the work of many scientists, such as Aksyutina Z.M., Alexandrov S.N., Balykin P.A. [4], Bogdanov N.I., Bronstein A.M., Voinarovich Andras, Gerasimov Yu.L. [5], Grigoriev S.S., Mot-Poulsen Thomas, Sedova N.A., Hoychi György [6] and others.

The object of our study was a farm for artificial fish farming, located in the Rostov region. Artificial reservoirs - is a system of earthen ponds for long-term fish keeping and a nearby complex of concrete pools intended for short-term fish keeping after hormonal stimulation.

The earthen pond has a total length of $130 \mathrm{~m}$ and consists of two parts: the main

* Corresponding author: mariazharkova@mail.ru 
widened $(100 \mathrm{~m})$ part, which has a depth of $2.5 \mathrm{~m}$, and a narrowed $(30 \mathrm{~m})$ shallower part $(0.5-1.0 \mathrm{~m})$, in which create conditions that mimic the approach to the spawning pool (high water flow rate and a pebbled bottom).

Females and males are kept separately in ponds. The water consumption in ponds is set at the beginning of the maintenance period at the level of $30-401 / \mathrm{s}$, at the end of prespawning holding it is increased to $300 \mathrm{l} / \mathrm{s}$.

The ponds for rearing sturgeon fry are rectangular in shape with an aspect ratio of $1: 2$ or $1: 3$. The area of the ponds is $1-4$ ha, the maximum depth is $2.5 \mathrm{~m}$; the bed has a slight slope.

The water supply network of the pond area consists of a main canal and side branches, suitable for each pond. Hydraulic structures of ponds ensure that each pond is filled with water and discharged within 1-2 days.

The process of water pollution in general can be expressed in the form of a balance diagram (Figure 1) using the example of an artificial fish farming enterprise in the Rostov region.

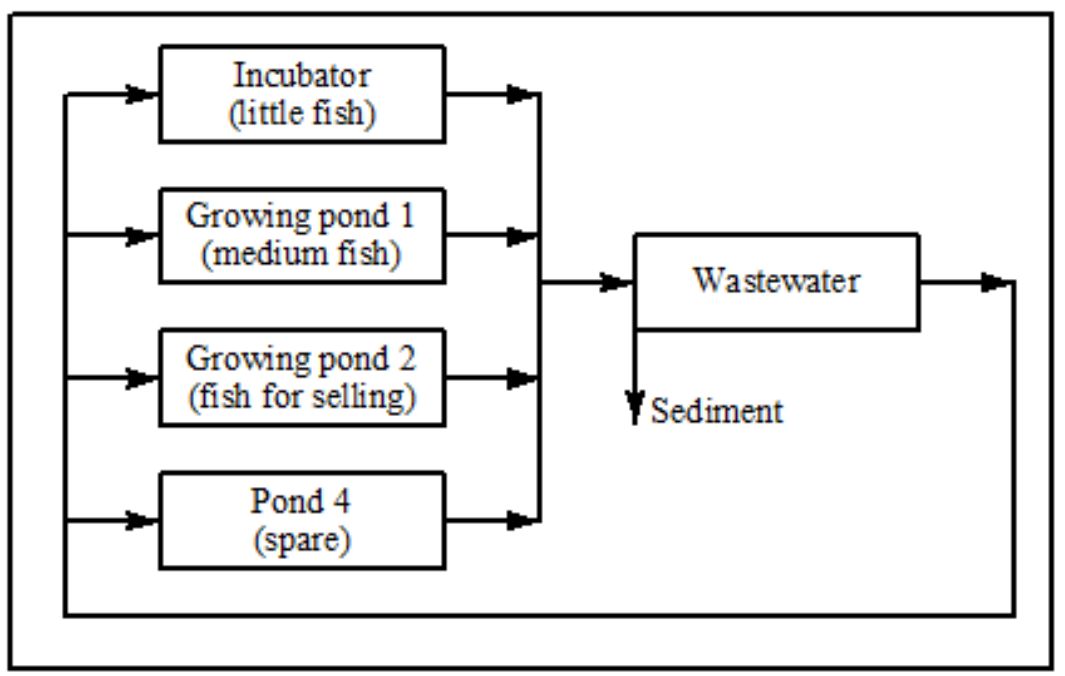

Material flow balance sheet for an enterprise

Fig. 1. Balance diagram $[7,8]$ of material flows on the example of an artificial fish farming enterprise in the Rostov region: 1 - water intake; 2 - sturgeon fry; 3 - growth promoters, manure

Balance equation: $100 \%$ sturgeon fry + feeding + medications + disinfectants + fertilizers $=$ marketable fish $40 \%+$ sludge (organic matter, fertilizer residues).

As sources of pollution of the aquatic environment, we considered: incubation shop, where fry develop, nursery pond №1 with underyearlings and nursery ponds №2 and 3 with marketable fish.

For the development of sturgeon fish, additional fertilizing, medicines, disinfectants and fertilizers are added to the water of ponds. As a result of dilution, dissolution and other processes, waste water and organo-mineral sludge are formed.

Contaminants $(\mathrm{Cm})$, ending up into the river (in our case to the Don river) with sewage, subject to intensive dilution. Initial dilution occurs due to the ejection of the surrounding water by a turbulent jet stream as waste water flows out of the outlet. In this zone, there is a significant decrease in the initial $\mathrm{Cm}$ concentrations (heavy metals). Further dilution is due to the effects of $\mathrm{Cm}$ turbulent diffusion of pollutants in the mixed flow. Further, there is a complete dilution of wastewater due to the effects of self-purification. 


\section{Materials and Methods}

For the detailed analysis of the participation of sturgeon breeding technology in water pollution of natural water bodies, we have built a physical model [8-11] of water pollution process, presented in Figure 2, the essence of which is the implementation of successive stages of transformation of raw materials into polluted water, at each of which the corresponding objects. Substances dissolved or settled in polluted water, going through all stages of interaction, undergo quantitative and qualitative changes.

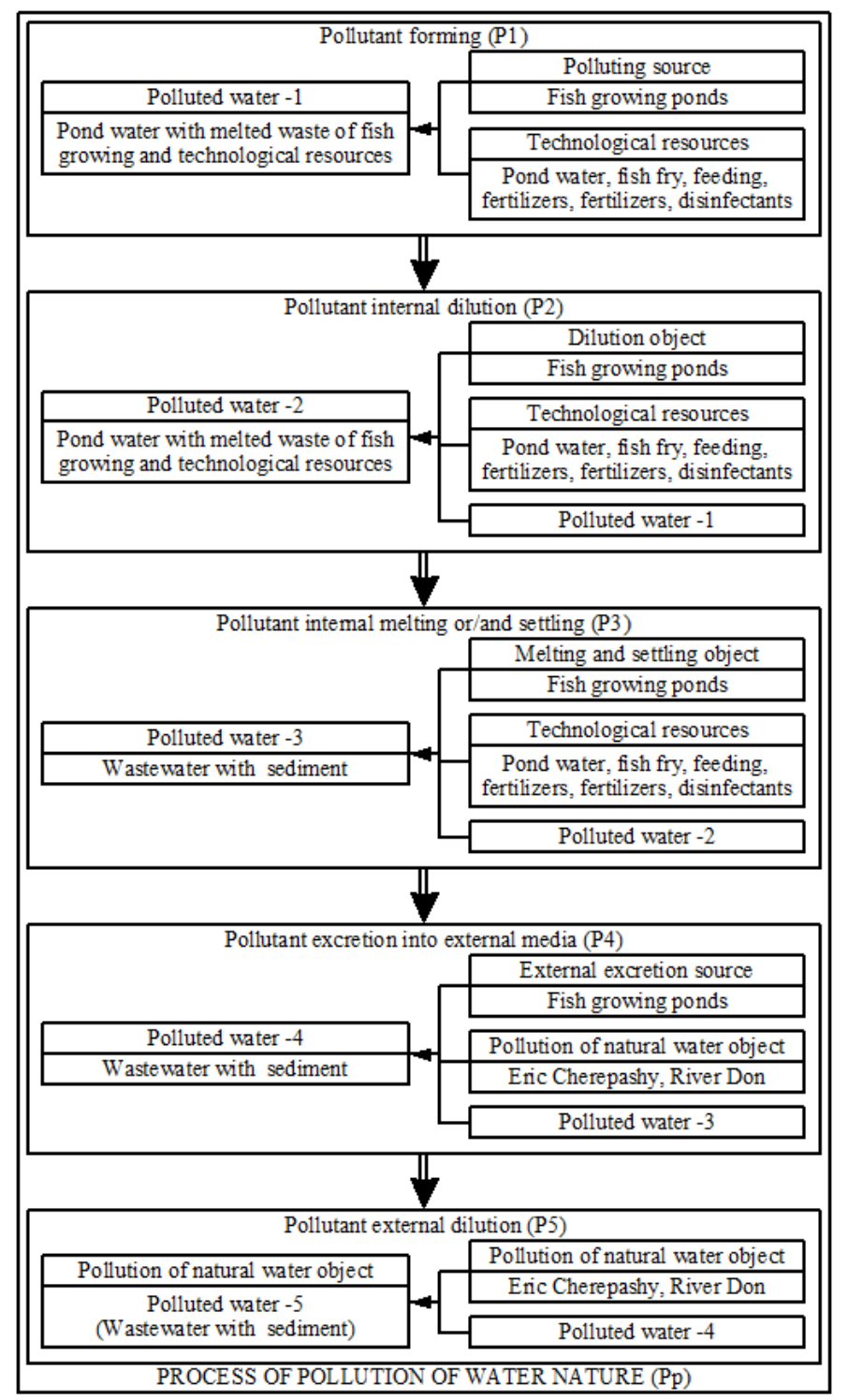

Fig. 2. Physical model of the water pollution process

The construction of a physical model of the process of pollution of the aquatic environment was carried out by the method of analyzing the parameters that characterize the objects involved in the process of pollution of the aquatic environment and determine, 
as a result, the features of pollution of the water body [10,11].

Taking into account the complexity of direct and feedback links between objects, a systematic approach to the analysis of the parameters inherent in each selected object was also used..

As shown in Figure 2, the process of water pollution includes five main stages.

In the process of formation of polluted water, the main objects interacting with each other are the source of $\mathrm{Cm}$ formation (ponds for breeding sturgeon fish) and technological raw materials (pond water, sturgeon fry, feeding, medications, disinfectants, fertilizers).

The implementation of the second stage involves two stages:

- internal dilution, the main physical objects of which are the object of dilution, polluted water and process raw materials;

- internal dissolution/subsidence, carried out by the interaction of pond water with dissolved elements of technological raw materials and fish waste products.

External selection and $\mathrm{Cm}$ external propagation processes, which are the 4th and 5 th stages of the process of water pollution, suggests the spread of $\mathrm{Cm}$ in the aquatic environment, in which a surface water source (the Don river) and polluting solutes participate as the main physical objects.

The physical model of the process of water pollution that we constructed made it possible to identify and trace the phased interaction of external systems acting to reduce pollution, with $\mathrm{Cm}$ at every stage of the water pollution process [10-12].

The main goal of each stage of reducing pollution of the aquatic environment is the destruction of pollution and their sedimentation.

Thus, in our opinion, the process of reducing pollution of the aquatic environment involves two cycles:

1 cycle-«Reducing pollution at source, in which substances are diluted/dissolved». The main purpose of this cycle is to prevent the release of dissolved/settled contaminants from the pond into an open surface water body (Don river).

The cycle includes two main stages, according to [4-8, 13-15]:

- «dirt binding», that is, the formation of organo-mineral sludge. The main goal of this stage is to prevent the process of pollution of the water environment of the object (pond) due to the targeted impact on the dissolved raw materials;

- «retention of contaminants before discharging water from a pond into a surface water body», the main purpose of which is to prevent the process of release of pollution from the volume of the pond through the use of hydraulic structures.

2 cycle - «Reducing pollution of surface water bodies». The implementation of this cycle is focused on the suspended state of pollution and is associated with the release and distribution of these substances in a surface water body. The main purpose of the cycle is to separate contaminants from water.

This cycle includes wastewater treatment and dilution in a natural water body of water discharged from ponds and treatment of sediments by the following methods [10-18].

- «contaminated water treatment» is carried out by mechanical, chemical, physicochemical, biological methods. The physical essence of the purification process lies in the targeted impact on the transported polluted water, prepared in advance according to the parameters.

- «dilution in a natural body of water discharged from ponds», the purpose of which is to intensively remove $\mathrm{Cm}$ particles when they are released into the aquatic environment of a surface reservoir.

\section{Results}

Based on the analysis, we have built a physical model of the process of reducing pollution of the aquatic environment for ponds intended for breeding sturgeon fish (Figure 3 ). 
I cycle - Reduced contamination of process equipment

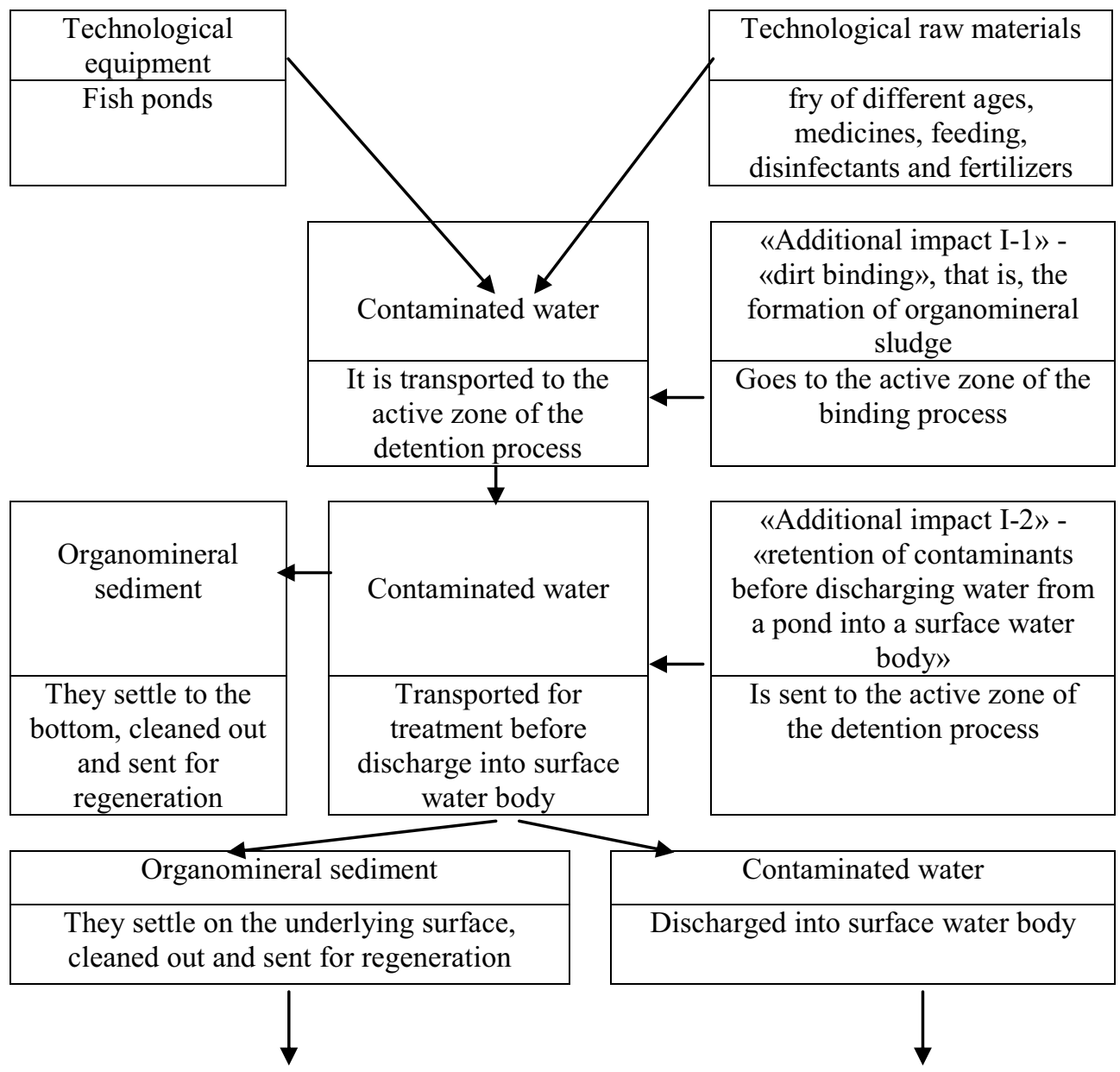

II cycle - Reducing pollution of surface water bodies

\begin{tabular}{|c|c|c|}
\hline & Contaminated water & $\begin{array}{l}\text { «Additional impact II-2» } \\
\text { Cleaning }\end{array}$ \\
\hline & $\begin{array}{l}\text { It is transported to the } \\
\text { active zone for the } \\
\text { implementation of the } \\
\text { dilution process in a } \\
\text { surface water body }\end{array}$ & $\begin{array}{l}\text { Sent to the active zone of } \\
\text { the cleaning process }\end{array}$ \\
\hline & $\downarrow$ & \\
\hline $\begin{array}{l}\text { Organomineral } \\
\text { sediment }\end{array}$ & Contaminated water & $\begin{array}{c}\text { «Additional impact II-3» } \\
\text { Dilution }\end{array}$ \\
\hline They settle on the & Transported to surface & Sent to the active zone of \\
\hline
\end{tabular}




\begin{tabular}{|c|c|c|}
\hline $\begin{array}{c}\text { underlying surface, } \\
\text { cleaned out and sent for } \\
\text { regeneration }\end{array}$ & water body (Don river) & $\begin{array}{c}\text { the dilution process in a } \\
\text { surface water body }\end{array}$ \\
\hline \multicolumn{1}{|c|}{$\begin{array}{c}\text { Organomineral sediment } \\
\text { cleaned out and sent for regeneration }\end{array}$} & $\begin{array}{c}\text { It is distributed in the surface water } \\
\text { body after the implementation of the } \\
\text { dilution process }\end{array}$ \\
\hline
\end{tabular}

Fig. 3. Physical model of the process of reducing water pollution [18-19].

Analysis of the physical model makes it possible to study in stages the process of reducing pollution of the aquatic environment and to select or develop environmental protection measures for specific production conditions, in which certain impacts will be consistently exerted on polluted water [10-16].

\section{Conclusions}

Engineering solutions aimed at ensuring the quality standards of the aquatic environment for the considered production conditions include the following designs:

1. Pumping station that takes water for the needs of fish farming;

2. Sediment storage tank (purifier pond), designed for water treatment, that is, to settle the water before it is fed into the fish ponds. Sediment from the settling tank - from the storage tank, as well as from the ponds, it is directed to the settling tank, from where the clarified water is directed through the water channel to the surface water body (the Don river), and the formed sediment to the sludge platform;

3. Single block of aeration tanks with primary and secondary sedimentation tanks;

4. The receiver of treated wastewater is the Don river.

Thus, as a result of the climatic conditions of the ponds' location analysis, the hydrochemical regime of water bodies, as well as the technological cycle of reproduction and cultivation of sturgeon fish species, favorable conditions have been established for use in fishery. In turn, analysis and identification of promising technologies for purification of natural waters from pollution made it possible to determine the optimal methods and constructive solutions for implementation of purification of polluted waters process discharged into surface water body after activities of enterprises for artificial fish farming.

\section{References}

1. V. Buyarov, Yu. Yushkova, A. Buyarov, Bulletin of the Voronezh state agrarian University, 12(1), 161-168 (2019)

2. S. Ponomarev. Science and Society at the Crossroads. International Symposium on sturgeon, 5, 171 (Canada, Nanaimo, Aquaculture Book, 2013)

3. T. J. Kinney, Biomass Bioenergy, 41, 34 (2012)

4. P. Balykin, et al., Economic problems of development of the fishing industry and economy of Russia in the light of the implementation Of the concept of development of the fishing industry of the Russian Federation, 78-86 (2020)

5. Yu. Gerasimov, Proceedings of the Samara scientific center of the Russian Academy of Sciences, 12, 1-4 (2010) 
6. D. Hoichi, Guide to artificial reproduction of trout in small volumes. Gyorgy Choice, Andras Woynarovich, Thomas Moth-Poulsen. Budapest, 20 (2012)

7. Biomass for Power Generation, Power Sector Issue 5/5 (2012)

8. S. Barinova, International Journal of Oceanography \& Aquaculture, 1(3), 1-9 (2017)

9. S. Barinova. International Journal of Environmental Sciences \& Natural Resources, 2(2), 1-8 (2017) doi: 10.19080/IJESNR. 2017.02.555581

10. S. Barinova, International Journal of Environmental Sciences \& Natural Resources, 3(2), 36-42 (2017) doi: 10.19080/IJESNR.2017.03.555608.

11. A. Protasov, S. Barinova, T. Novoselova, A. Sylaieva. Diversity, E190, 1-17, 11(10) (2019) doi: 10.3390/d11100190.

12. S. Barinova, International Journal of Environmental Sciences \& Natural Resources, 2(3), 1-11 (2017) doi: 10.19080/IJESNR.2017.02.555588

13. S. Tazhieva, L. Boronina, N. Serpokrylov. Prospects for the development of the construction complex: materials of the 6-th International scientific-practical conf, 1, $240-242$ (2013)

14. L. Dolzhenko, Education and science in the modern world, Innovation-Penza, 5(12), 52-62 (2017)

15. A. Pyshmantseva. Ecology of river landscapes, 207-223 (2017)

16. V. Scriabin . NIRS - the first stage in science, 130-134 (2016)

17. N. Batislava etc. Biology and medicine (2014)

18. V. Chalov, E. Ponomareva, Bulletin of the Astrakhan state technical University. Series: fisheries, 1 (2010)

19. N. Rabazanov, M. Shikhshabekov, South of Russia: ecology, development, 4 (2011) 